\title{
Mendelian Inheritance
}

National Human Genome Research Institute (NHGRI)

\section{Source}

National Human Genome Research Institute (NHGRI). Mendelian Inheritance.

Huntington's Disease

Dominant

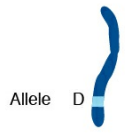

1
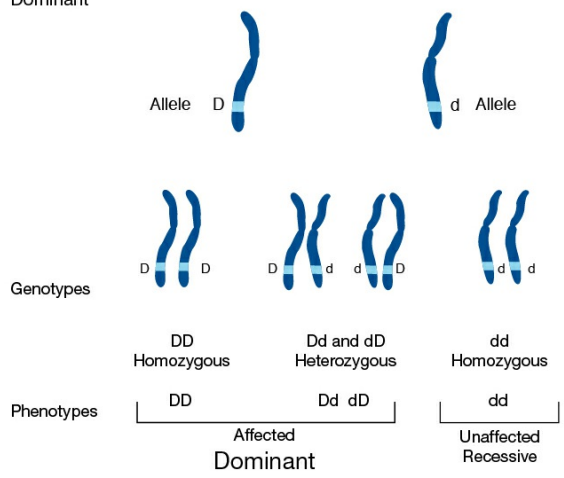

Hemophilia

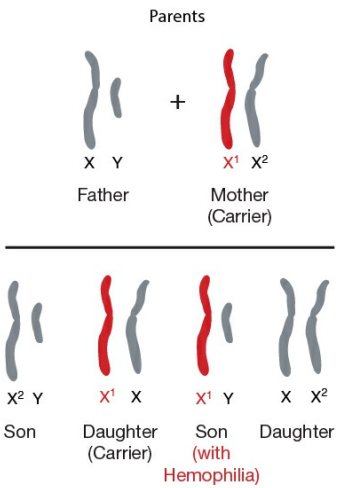

Sickle Cell Anemia or Cystic Fibrosis

Recessive
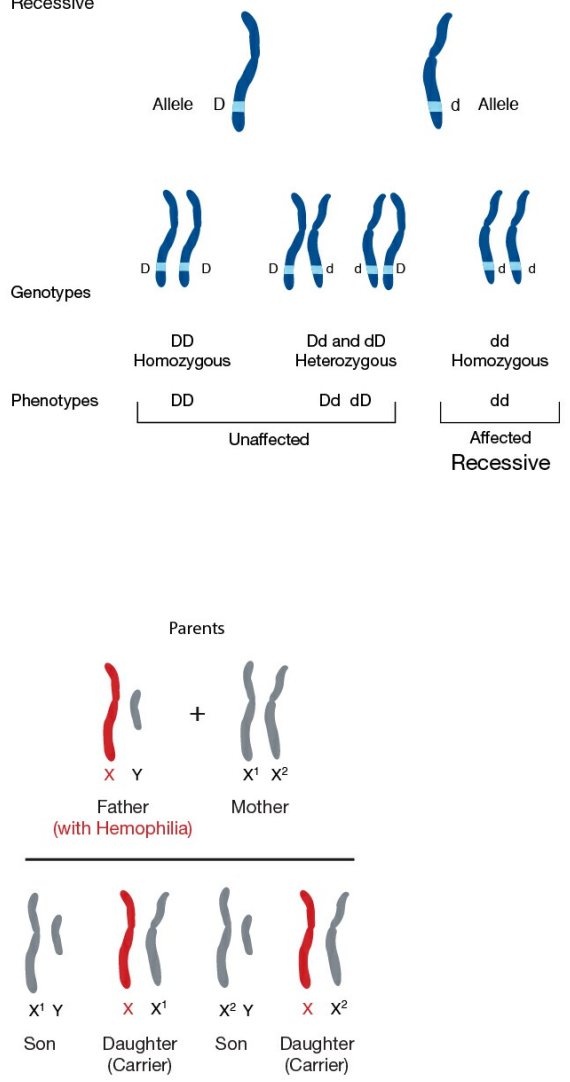

Mendelian inheritance refers to patterns of inheritance that are characteristic of organisms that reproduce sexually. The Austrian monk Gregor Mendel performed thousands of crosses with garden peas at his monastery during the middle of the 19th century. Mendel explained his results by describing two laws of inheritance that introduced the idea of dominant and recessive genes. 